\title{
Acute kidney injury after lung transplantation: a narrative review
}

\author{
Lei Jing ${ }^{1,2,3,4,5,6}$, Wenhui Chen ${ }^{2,3,4,5,6}$, Lijuan Guo ${ }^{2,3,4,5,6}$, Li Zhao ${ }^{2,3,4,5,6}$, Chaoyang Liang ${ }^{2,3,4,5,6}$, \\ Jingyu Chen ${ }^{2,3,4,5,6}$, Chen Wang ${ }^{1,2,3,4,5,6}$
}

${ }^{1}$ Chinese Academy of Medical Sciences and Peking Union Medical College, Beijing, China; ${ }^{2}$ Department of Lung Transplantation, Centre of Lung Transplantation, Centre of Respiratory Diseases, China-Japan Friendship Hospital, Beijing, China; ${ }^{3}$ National Center for Respiratory Medicine, Beijing, China; ${ }^{4}$ Institute of Respiratory Medicine, Chinese Academy of Medical Sciences, Beijing, China; ${ }^{5}$ National Clinical Research Center for Respiratory Diseases, Beijing, China; ${ }^{6}$ WHO Collaborating Centre for Tobacco Cessation and Respiratory Diseases Prevention, Beijing, China

Contributions: (I) Conception and design: J Chen, C Wang, L Jing; (II) Administrative support: None; (III) Provision of study materials and patients: L Jing, W Chen; (IV) Collection and assembly of data: L Jing, L Guo, L Zhao, C Liang; (V) Data analysis and interpretation: L Guo, L Zhao, C Liang; (VI) Manuscript writing: All authors; (VII) Final approval of manuscript: All authors.

Correspondence to: Jingyu Chen, MD. Director of the Department of Lung Transplantation, Professor of Thoracic Surgery, China-Japan Friendship Hospital, No. 2 Yinghua East Road, Chaoyang District, Beijing 100029, China. Email: chenjy@wuxiph.com; Chen Wang, MD, PhD. President of Chinese Academy of Medical Sciences and Peking Union Medical College, Director of the Centre for Lung Transplantation, Professor of Clinical Medicine, China-Japan Friendship Hospital, No. 2 Yinghua East Road, Chaoyang District, Beijing 100029, China. Email: wangchen66366@163.com.

\begin{abstract}
Acute kidney injury (AKI) is a commonly recognized complication after lung transplantation (LT) and is related to increased mortality and morbidity. With the improvement of survival after LT and the increasing number of lung transplant recipients, the detrimental impact of current management on renal function has become increasingly apparent. Multifarious risk factors in the perioperative setting contribute to the development of AKI, including the preoperative status and complications of the recipient, complex perioperative problems especially hemodynamic fluctuation, and exposure to nephrotoxic agents, mainly calcineurin inhibitors (CNIs) and antimicrobial drugs. Identification and minimization of the effects of these risk factors can relieve AKI severity and incidence in high-risk patients. Close monitoring of urine output and serum creatinine $(\mathrm{sCr})$ levels and of specific biomarkers may promote early recognition of AKI and rapid nephrology intervention to improve outcomes. This review summarizes advances in the epidemiology, diagnostic criteria, biological markers of AKI, and further recommends appropriate treatment strategies for the long-term management of AKI related manifestations in lung transplant recipients. Future work will need to focus on developing more accurate measures of renal function and identifying patients before the occurrence of early renal damage. Combining renal protection strategies with the use of new biomarkers to develop early kidney risk identification and protection protocols is a promising idea that requires further investigation.
\end{abstract}

Keywords: Acute kidney injury (AKI); lung transplantation (LT); incidence; risk factors; impact and management

Submitted Nov 25, 2020. Accepted for publication Feb 04, 2021.

doi: 10.21037/atm-20-7644

View this article at: http://dx.doi.org/10.21037/atm-20-7644

\section{Introduction}

Acute kidney injury (AKI), which commonly occurs following lung transplantation (LT), is a syndrome involving a rapidly dropping glomerular filtration rate (GFR) in response to acute stressors and leads to increased morbidity and mortality (1). Despite prominent improvements in medical management and lung surgery, the mortality and epidemiology of AKI after LT remain unclear. This review summarizes advances in the epidemiology, diagnostic criteria, biological markers and prevention and treatment strategies of AKI with the objective of providing a better understanding of the mechanisms that promote AKI for the optimization of monitoring and management methods to minimize this important source of morbidity and mortality. 
Table 1 Staging of acute kidney injury (AKI) based on different criteria

\begin{tabular}{|c|c|c|c|c|c|}
\hline Different criteria & Stage 1 (RIFLE risk) $)^{\dagger}$ & Stage 2 (RIFLE injury) ${ }^{\dagger}$ & Stage 3 (RIFLE failure) ${ }^{\dagger}$ & RIFLE loss ${ }^{\dagger}$ & $\begin{array}{c}\text { RIFLE end } \\
\text { stage }^{\dagger}\end{array}$ \\
\hline $\begin{array}{l}\text { RIFLE (2004) } \\
\text { (within } 7 \text { d) }\end{array}$ & $\begin{array}{l}\text { (I) sCr increase } \times 1.5 \\
\text { (II) eGFR loss }>25 \% \\
\text { (III) } U O<0.5 \mathrm{~mL} / \mathrm{kg} / \mathrm{h} \\
\text { for over } 6 \mathrm{~h}\end{array}$ & $\begin{array}{l}\text { (I) sCr increase } \times 2.0 \\
\text { (II) eGFR loss }>50 \% \\
\text { (III) } U O<0.5 \mathrm{~mL} / \mathrm{kg} / \mathrm{h} \\
\text { for over } 12 \mathrm{~h}\end{array}$ & $\begin{array}{l}\text { (I) } \mathrm{sCr} \text { increase } \times 3.0 \\
\text { (II) } \mathrm{sCr} \geq 4.0 \mathrm{mg} / \mathrm{dL} \\
(\geq 354 \mu \mathrm{mol} / \mathrm{L}) \\
\text { (III) eGFR loss }>75 \% \\
\text { (IV) Anuria for over } 12 \mathrm{~h} \\
\text { (V) UO }<0.3 \mathrm{~mL} / \mathrm{kg} / \mathrm{h} \\
\text { for over } 24 \mathrm{~h}\end{array}$ & $\begin{array}{c}\text { Persistent } \\
\text { acute renal } \\
\text { failure for } \\
\text { over } 4 \text { weeks }\end{array}$ & $\begin{array}{l}\text { ESRD for } \\
\text { over } \\
3 \text { months }\end{array}$ \\
\hline $\begin{array}{l}\text { AKIN (2007) } \\
\text { (within } 48 \text { h) }\end{array}$ & $\begin{array}{l}\text { (I) } \mathrm{sCr} \text { increase } \geq 0.3 \mathrm{mg} / \mathrm{dL} \\
(\geq 26.5 \mu \mathrm{mol} / \mathrm{L}) \\
\text { (II) } \mathrm{sCr} \text { increase } \times 1.5 \\
\text { (III) } \mathrm{UO}<0.5 \mathrm{~mL} / \mathrm{kg} / \mathrm{h} \\
\text { for over } 6 \mathrm{~h}\end{array}$ & $\begin{array}{l}\text { (I) } \mathrm{sCr} \text { increase } \times 2.0 \\
\text { (II) } \mathrm{UO}<0.5 \mathrm{~mL} / \mathrm{kg} / \mathrm{h} \\
\text { for over } 12 \mathrm{~h}\end{array}$ & $\begin{array}{l}\text { (I) } \mathrm{sCr} \text { increase } \times 3.0 \\
\text { (II) } \mathrm{sCr} \geq 4.0 \mathrm{mg} / \mathrm{dL} \\
(\geq 354 \mu \mathrm{mol} / \mathrm{L}) \\
\text { (III) Initiation of RRT } \\
\text { (IV) Anuria for over } 12 \mathrm{~h} \\
\text { (V) } U O<0.3 \mathrm{~mL} / \mathrm{kg} / \mathrm{h} \\
\text { for over } 24 \mathrm{~h}\end{array}$ & & \\
\hline
\end{tabular}

${ }^{\dagger}$, need only 1 criterion for diagnosis. $\mathrm{sCr}$, serum creatinine; UO, urine output; eGFR, estimated glomerular filtration rate; RRT, renal replacement therapy; ESRD, end-stage renal disease.

We present the following article in accordance with the Narrative Review reporting checklist (available at http:// dx.doi.org/10.21037/atm-20-7644).

\section{Methods}

This study was identified via an electronic search of PubMed database (updated to August 2020) by two authors (LJ and WC). The languages were limited to English. The search terms used were "acute kidney injury" or "renal injury" or "renal failure" or "renal dysfunction" or "kidney disease", combined with "lung transplantation". The "similar articles" function was used to broaden the search.

Reference list for selected articles were searched to get additional relevant records.

\section{Diagnostic criteria and staging of AKI}

Since 2004, the diagnostic criteria for AKI have successively evolved into the following three standards: the Risk, Injury, Failure, Loss, and End-stage kidney disease (RIFLE) criteria (2), the Acute Kidney Injury Network (AKIN) criteria (3), and the Kidney Disease: Improving Global Outcomes (KDIGO) criteria (4). Among them, the RIFLE criteria do not consider the influence of age, sex and other factors on the serum creatinine (sCr) level (2), and the diagnosis time of AKI within the AKIN criteria is limited to $48 \mathrm{~h}$, resulting in missed diagnoses of patients with slow changes in sCr (3). In 2012, the KDIGO criteria were issued, and these criteria not only extend the diagnosis time but also have a certain predictive value in determining the prognosis of AKI patients; therefore, these criteria have become the most widely used AKI diagnostic standard $(4,5)$. Based on the KDIGO criteria, AKI is defined by an increase in sCr of at least $0.3 \mathrm{mg} / \mathrm{dl}$ or a $50 \%$ increase over baseline within 48 hours with or without reduced urine output $(<0.5 \mathrm{~mL} / \mathrm{kg}$ per hour) (6). The specific staging of AKI is shown in Table 1.

\section{Incidence and mortality of AKI}

Recently, AKI has been reported to be observed in 33-69\% of LT patients, with $17-37 \%$ of LT patients having stage 2-3 AKI and 5-13\% needing renal replacement therapy 
(RRT) (7-11). The mortality rate of AKI is $16-50 \%$ and is strongly related to AKI stage, etiology and patient comorbidities $(12,13)$.

\section{Risk factors for AKI}

\section{Preoperative factors}

\section{Respiratory failure}

Recent studies have highlighted the complexity of organorgan interactions between the kidney and the lung. The common characteristics of lung injury and the compensatory mechanisms of injury are acidosis and blood gas disorders (14). Additionally, it has been reported that low oxygen and/or high carbohydrate levels can have an impact on renal blood flow and water and salt excretion, which contribute to renal dysfunction (15).

\section{Right-sided heart failure}

The proportion of lung transplant candidates with cor pulmonale is very high. Right ventricular congestive states and dysfunction may result in reverse effects of compensatory neurohormonal mechanisms, for example the renin-angiotensin-aldosterone system, high venous pressure and edema, and changes in kidney perfusion and oxygenation, leading to escalating doses of diuretics and renal injury $(14,16)$. In addition, recent findings illustrate that venous hyperemia can increase intracapsular pressure through renal compartment syndrome formation, thereby reducing renal perfusion pressure and oxygen supply (17). Central venous pressure (CVP), one of the most important hemodynamic determinants of renal function deterioration, is related to increased mortality as a surrogate indicator of right ventricular injury (18).

\section{Advanced age}

A decline in kidney function is closely associated with aging, and elderly patients are more prone to AKI $(19,20)$. As the success rate of LT has improved, an increasing number of elderly patients have become LT recipients. Due to intraoperative bleeding, the use of nephrotoxic agents, and perioperative hemodynamic instability, elderly patients have a high risk of rapid renal loss after LT $(11,21)$.

\section{Hypertension and diabetes mellitus}

Both hypertension and diabetes mellitus are connected with a high risk of chronic kidney disease (CKD) (22-24). LT patients with pretransplant hypertension $(20,25)$ and diabetes mellitus $(8,20,26,27)$ have been shown to be at high risk of AKI after LT. Careful surveillance and control of blood pressure and blood glucose after transplantation are essential to prevent postoperative AKI.

\section{Higher baseline creatinine}

A study in an early entirely adult cohort indicated that a change in baseline renal function can predict the prognosis of renal outcomes after LT (21). Studies have demonstrated that recipients with a high baseline creatinine level or preexisting renal impairment have the greatest risk of rapid renal function loss and that these factors are independently associated with posttransplant AKI $(7,8,11,21,26-28)$. Because a higher baseline creatinine level reflects potentially less "renal reserve", such patients cannot tolerate hemodynamic variation and other renal toxicity damage during or after transplantation and may predictably be at higher risk for AKI.

\section{Preoperative mechanical ventilation (MV)}

Generally, MV and intubation are requested in endstage lung disease patients to improve gas exchange and oxygenation. However, studies have indicated that MV induces hemodynamic and neurohormonal alterations and is associated with renal water retention (14). Biological trauma resulting from injurious ventilation tactics can contribute to the migration of pro-inflammatory factors to the lung, which are then transferred to the systemic circulation, causing terminal organ dysfunction, such as AKI (14). A 3 -fold increased risk of AKI has been reported in patients with acute respiratory distress syndrome (ARDS) after MV treatment (29). This indicates that ARDS and MV are both independently related to the prognosis of AKI $(16,27,30)$, and $35-60 \%$ of patients who develop multiorgan failure after MV need RRT (31).

\section{Extracorporeal membrane oxygenation (ECMO)}

Pretransplant ECMO is demonstrated to be a clear risk factor for AKI after LT $(16,26,27)$. The incidence of AKI in patients with ECMO has been reported to be over $70 \%$, and approximately $50 \%$ of the patients received RRT (32). The major mechanisms may contribute to renal hypoperfusion, prolonged hypoxemia (ischemia) before ECMO and reperfusion injury after ECMO initiation, 
Table 2 Risk factors contributing to acute kidney injury (AKI) after lung transplantation

\begin{tabular}{|c|c|c|}
\hline Preoperative factors & Intraoperative factors & Postoperative factors \\
\hline Smoking history & Blood loss & Diuretic use \\
\hline Higher baseline creatinine & Hemodynamic instability & Calcineurin inhibitors \\
\hline Higher BMI & Blood transfusion & Sepsis \\
\hline ECMO & Diuretic use & Prolonged ECMO \\
\hline Right-sided heart failure & Hypoxia $\left(\mathrm{SpO}_{2}<90 \%\right)$ & Rhabdomyolysis \\
\hline Diabetes mellitus & Ischemic time (>6 h) & Hemolytic uremic syndrome \\
\hline Hypertension & HES volume & Acute interstitial nephritis \\
\hline \multicolumn{3}{|l|}{ Higher lung allocation score } \\
\hline \multicolumn{3}{|l|}{ Retransplantation } \\
\hline Nephrotoxic agents ${ }^{\S}$ & & \\
\hline
\end{tabular}

microvascular dysfunction and endothelial damage caused by the artificial membrane contact with blood, hemodynamic fluctuations and cannula position dislocation leading to venous obstruction/arterial insufficiency $(14,33)$. A metaanalysis conducted by Thongprayoon et al. showed that AKI requiring RRT while on ECMO is related to 3.7-fold increased risk of hospital mortality (34). In patients undergoing ECMO, close monitoring of kidney function is necessary because fluid overload and AKI easily develop in these patients.

\section{Cystic fibrosis (CF)}

CF has been demonstrated to be an independent factor for AKI after LT, and patients with CF tend to have preexisting renal disease prior to LT (20,35-37). The causes of renal insufficiency in patients with CF vary but include abnormal calcium metabolism, nephrotoxic drug exposure, and diabetes (38). As part of Pseudomonas aeruginosa management strategies, nephrotoxic antibiotics, such as aminoglycosides, are very commonly used in CF patients (35). In addition, approximately $80-90 \%$ of CF patients exhibit pancreatic exocrine dysfunction, and $30-50 \%$ of CF patients develop diabetes after LT (38). More than $90 \%$ of patients with CF present medullary renal calcification at autopsy, accompanied by a significantly increased incidence of urolithiasis, which may indicate primary abnormal cities in renal calcium metabolism $(35,39)$.

Other risk factors for AKI include a smoking history $(21,27,40)$, high body mass index (BMI) (26), high lung allocation score $(16,27,41)$, pulmonary hypertension $(\mathrm{PH})$ $(16,27)$, retransplantation $(16,27)$ and nephrotoxic agent exposure $(7,16,35)$. Recipients with these risk factors before transplantation have a high risk of kidney injury after transplantation. Thus, to better protect renal function, aggressive risk factors should be modified or treated before LT whenever possible (Table 2).

\section{Intraoperative factors}

\section{Type of transplant}

Bilateral lung transplantation (BLT) has been reported to be another independent risk factor for AKI, with a posttransplant AKI incidence of 39-62\%, which may be 
due to a longer operating time, increased use of ECMO, higher bleeding risk, and increased blood transfusion rate (7,9,10,25-27,42-44). Studies have also suggested that lung surgery can induce renal epithelial apoptosis by releasing inflammatory mediators and renal hypoperfusion by generating fluid retention, further causing AKI (11).

\section{Blood loss and bemodynamic instability}

The kidney is very sensitive and has poor tolerance for hypotension and hypoxia (45). Excessive blood loss during surgery causes systemic hemodynamic instability, leading to decreased effective blood flow and renal hypoxia and even inducing necrosis of renal tubular epithelial cells. On the other hand, low renal perfusion may cause endothelial release of angiotensin and other vasoconstriction factors, which brings about a further reduction in renal blood flow and aggravation of renal ischemia (45). Numerous studies have indicated that hemodynamic instability and intraoperative blood loss are risk factors that cannot be overlooked in AKI after LT $(25,42-44,46)$.

\section{Blood product transfusion}

Intraoperative blood transfusion has been identified as an independent risk factor for AKI $(25,42,43,47)$, although the volume and proportions of these blood products related to AKI risk have not been determined. The reasons may be that blood transfusion is an indicator of low blood volume due to hemorrhage and renal ischemic injury and that transfusions may lead to kidney injury through over resuscitation and tissue edema accompanied by a systemic inflammatory response $(45,47)$.

\section{High dose of catecholamines}

Vasopressor therapy remains the mainstay for maintaining blood pressure stability and tissue perfusion during LT. However, any therapy that increases the GFR increases renal oxygen consumption, potentially promoting a lack of oxygen in kidney tissue (48). Nguyen et al. indicated that intraoperative utilization of catecholamines elevated the risk of AKI after LT by 3-fold, even when the mean blood pressure was maintained at $>65 \mathrm{mmHg}$ (46). In refractory septic shock, administration of $0.5-1.0 \mu \mathrm{g} / \mathrm{kg} / \mathrm{min}$ (high dose) norepinephrine was related to increased mortality, ranging from $60-100 \%(49,50)$.

Other risk factors for intraoperative AKI include hypoxia
(<90\%) (43), high hydroxyethyl starch (HES) volume (43), ischemic time (>6 h) (11,27), and aprotinin in use (10) (Table 2).

\section{Postoperative factors}

\section{Volume depletion and diuretic use}

Pulmonary edema, either mild or severe, is very common after LT due to ischemia reperfusion injury, and management of these patients usually involves strategies to limit fluid intake and escalation of the doses of diuretics. Intravascular volume depletion and hypotension can cause renal vasoconstriction, aggravating renal hypoperfusion and hypoxia and even causing endothelial injury and tubular necrosis (51). Moreover, the relative capacity depletion of the patients makes them more susceptible to AKI under the condition of nephrotoxic agents, intravenous contrast dye, or calcineurin inhibitors (CNIs) $(16,35,51)$.

\section{Sepsis}

Complications from infection account for $19.5 \%$ of deaths within 3 to 5 years after LT (52). Sepsis is common in transplant recipients and is a major condition related to AKI occurrence in the intensive care unit (ICU) (approximately $50 \%$ of patients) $(16,35,51,53,54)$. The mechanisms include ultrafiltration of circulating microbial toxins that cause stress and injury to tubular cells and secretion of inflammatory cytokines and the microcirculatory flow reduction (51).

\section{Prolonged MV and/or ECMO}

AKI commonly occurs in patients with long-term MV and/or ECMO after LT. Studies have shown that either postoperative $M V>3$ days $(42,44)$ or a duration of ECMO support $>2$ days $(42,55)$ is an independent factor for AKI development in lung transplant patients. Studies have also demonstrated that treatment with RRT during ECMO support was linked to a high mortality rate both in adult $(34,56,57)$ and pediatric patients $(58)$. In patients who developed AKI, longer invasive MV or ECMO time after surgery has been shown to have a negative correlation with survival $(8,11,55)$.

\section{CNIs}

CNIs, such as cyclosporin A (CsA) and tacrolimus, remain the best treatment option for immunosuppression after LT. 
However, significant acute or chronic nephrotoxicity, such as renal thrombotic microangiopathy (TMA) $(16,59,60)$, hemolytic uremic syndrome (HUS) $(16,59)$, and acute/ chronic interstitial nephritis (AIN/CIN), is caused by CNIs $(16,59)$. CsA can increase levels of the vasoconstrictor endothelin and can reduce the generation of vasodilatory nitric oxide by endothelial cells, thus leading to a decrease in the GFR and renal blood flow $(61,62)$. A high blood level of tacrolimus has a significant effect on AKI, especially combined with prophylactic antimicrobial drugs in the early postoperative course $(16,35,63)$.

\section{Other nephrotoxic drugs}

To achieve adequate glomerular hyperfiltration, the renal vascular bed gains a significant portion of resting cardiac output (20-25\%), which exposes the interstitium, renal vasculature system and nephrons to a large amount of blood-derived toxins (51). LT patients are frequently exposed to multiple nephrotoxic drugs in the early postoperative period, such as aminoglycosides, amphotericin, vancomycin, trimethoprimsulfamethoxazole, ganciclovir/valganciclovir, and nonsteroidal anti-inflammatory drugs (NSAIDs), which have been demonstrated to increase the risk of AKI $(16,35,64-66)$.

Other postoperative risk factors for AKI, such as contrast dye exposure $(16,35)$, HUS $(35,64)$, AIN $(35,64)$, TMA $(16,59,60)$, rhabdomyolysis (35) and rapid intravenous immunoglobulin infusion (35), have also been reported (Table 2).

\section{Impact of AKI}

LT patients with AKI have a higher risk of CKD and hypertension, including end-stage renal failure (67). According to a 2019 report from the International Society for Heart and Lung Transplantation (ISHLT), the prevalence of severe kidney dysfunction ( $\mathrm{sCr}>221 \mathrm{mmol} / \mathrm{L}$ ) and chronic dialysis was $4.8 \%$ and $3.4 \%$ at 1 year post-transplantation (68). At 10 years after transplantation, the cumulative incidence of severe kidney insufficiency was $24.6 \%$, with $6.3 \%$ of patients having chronic dialysis and $3.6 \%$ of patients receiving a kidney transplantation (68). Both AKI and CKD significantly affect patient survival after LT.

\section{Biomarkers of AKI}

\section{sCr and urine output}

At present, AKI is defined and staged according to urine output or sCr levels. However, sCr has low sensitivity because the level of sCr may not be enhanced until 24-72 h after AKI onset (69). Conversely, the specificity of urine output is low because this functional indicator can decline under the influence of several factors. In addition, the underlying functional and nutritional status of many LT recipients leads to muscle atrophy, and diagnosis of kidney injury using $\mathrm{sCr}$ or urine output can contribute to insufficient or prolonged identification of AKI events (16). Interpretation of the sCr level in children is also particularly difficult, with great variation according to age and sex and the method of measurement. Owing to the disadvantages of urine output and $\mathrm{sCr}$ levels in timely and reliable identification of AKI, there are increasing expectations for the development of novel biological markers that can be identified in the early stage of AKI, when interventions might be more successful. When individual risk stratification for AKI is possible, we can avert any unnecessary renal stress and even begin to perform preventive treatment (70).

\section{Neutrophil gelatinase-associated lipocalin (NGAL)}

NGAL, a protein that was first observed in neutrophil granules (71), can be synthesized innumerous human tissues and kidney epithelium. NGAL serves as a structural biomarker to predict AKI progression, is released by damaged tubular epithelial cells and increases rapidly in serum and urine (72-74). NGAL has been measured under a variety of conditions, such as cardiac surgery, sepsis, contrast dye exposure, and post-kidney transplantation, and the specificity and sensitivity of NGAL has been reported to range from $70-80 \%$, while the diagnostic accuracy ranges from $0.53-0.96$ based on the receiver operating characteristic (ROC) curve analysis (70,75-78). In particular, NGAL can also be released from neutrophils during inflammation (79). Consequently, inflammation is considered to be a confounding factor for NGAL as a biomarker of AKI in patients with sepsis in the ICU (80-82).

\section{Urine tissue inbibitor of metalloproteinase 2 (TIMP2) and insulin-like growth factor binding protein 7 (IGFBP7)}

TIMP2 and IGFBP7, which are both cell cycle arrest regulators, can reflect cell stress in the early stage of tubular cell injury $(83,84)$. TIMP2*IGFBP7 is considered a promising biomarker and has been found to facilitate prediction of AKI caused by a wide variety of insults $(70,85-88)$. 
Table 3 The most promising novel biomarkers for early identification of AKI

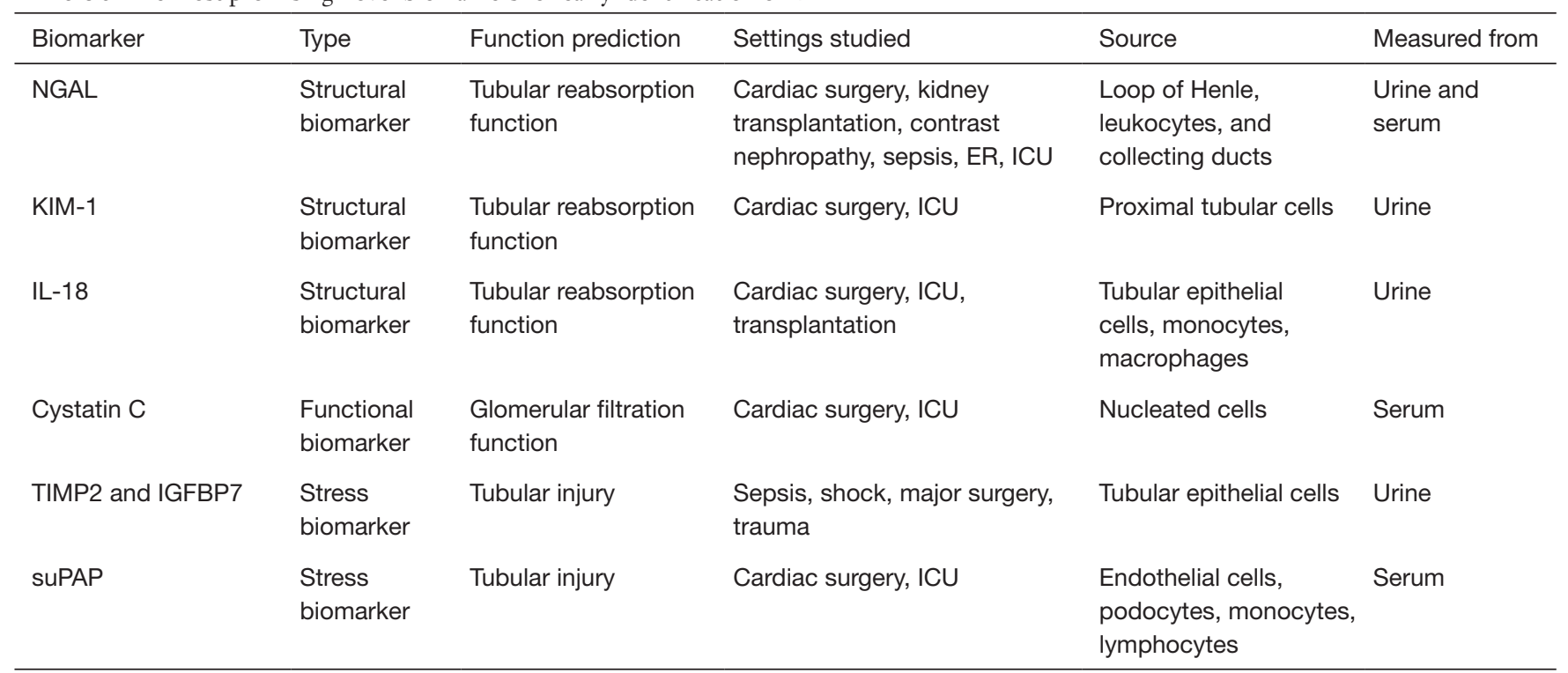

ER, emergency room; NGAL, neutrophil gelatinase-associated lipocalin; ICU, intensive care unit; IL-18, interleukin-18; suPAP, soluble urokinase plasminogen activator receptor; TIMP2, tissue inhibitor of metalloproteinases 2; KIM-1, kidney injury molecule-1; IGFBP7, insulin-like growth factor-binding protein 7.

A value of (TIMP2)*(IGFBP7) of more than 0.3 indicates a population at high risk for AKI, suggesting that preventive measures should be taken against AKI, including reducing renal toxins and improving hemodynamics (86).

\section{Kidney injury molecule-1 (KIM-1)}

KIM-1, a type I cell membrane glycoprotein, was originally identified through a representative differential analysis after renal ischemia-reperfusion injury (89). Studies have shown that KIM-1 may be a sensitive biomarker of AKI in patients with non-cardiac or cardiac surgery (90-93), and KIM-1 has been confirmed to be a useful indicator to distinguish acute tubular necrosis from other forms of AKI $(70,94)$.

\section{Interleukin-18 (IL-18)}

IL-18 is secreted by the intercalated cells of the collecting tubules of the kidney, the late distal convoluted tubule and the connecting tubule (95). The IL-18 level, which can change 1-2 d before the sCr level, has been shown to be a biomarker of AKI in the early stage $(96,97)$ and may be a predictor of death $(70,98)$.

\section{Cystatin C (Cys-C)}

Cys-C is a nuclear protein expressed in all nucleated cells. Cys-C can be freely filtered by the glomerulus and then reabsorbed and disintegrated in the proximal tubular cells (99). Serum Cys-C, which is considered a functional biomarker of AKI $(70,100,101)$, reflects glomerular filtration function and is a more accurate biomarker of renal function than the sCr level $(102,103)$. However, serum Cys-C seems to be affected by thyroid function, malignancy, inflammation, and high doses of corticosteroids $(104,105)$.

\section{Soluble urokinase plasminogen activator receptor (suPAR)}

suPAR is a signaling glycoprotein normally expressed at very low levels on endothelial cells, podocytes, monocytes and lymphocytes $(106,107)$. A recent study has reported that high levels of serum suPAR were related to AKI in patients undergoing coronary angiography, patients suffering from critical illness, and patients treated with cardiac surgery (108). The findings suggest that suPAR might serve as a novel biomarker, can be increased prior to AKI occurrence, and may be utilized to predict AKI (69). Moreover, suPAR may be pathogenic, and targeting suPAR might be a potential therapeutic strategy (69). suPAR is thought to have the potential to provide information for preprocedural risk-stratified and clinical decision-making care (69). Table 3 summarizes the most promising novel 


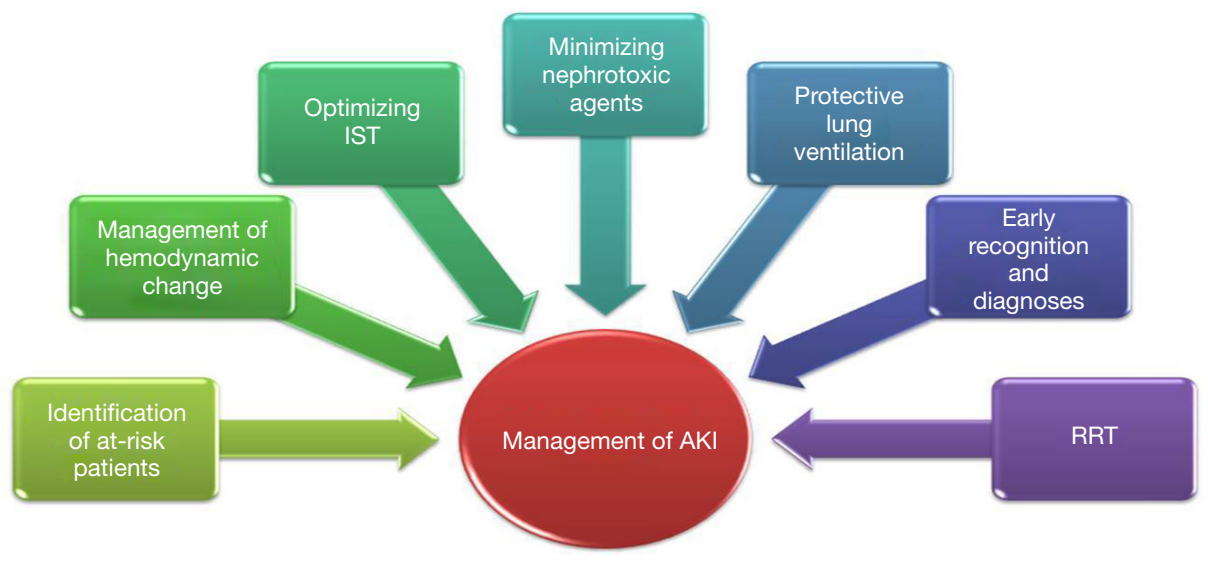

Figure 1 Approaches to prevent and manage AKI after lung transplantation. IST, immunosuppressive therapy; RRT, renal replacement therapy; AKI, acute kidney injury.

indicators for diagnosing AKI in the early stage.

\section{Prevention and management of AKI}

The final purpose of identifying biomarkers and risk factors is to ameliorate the prognosis. Early recognition of AKI and therapeutic methods to confine AKI occurrence and development are vital to decrease morbidity and mortality. Considering the high incidence of AKI after LT, it is essential to consider all available therapeutic schedules to support renal function (Figure 1).

\section{Identification of at-risk patients}

Identifying at-risk patients according to pretransplant risk factors and surgical procedures is essential. There are many types of AKI-associated factors. Generally, those at the highest risk are $\mathrm{CF}$ or $\mathrm{PH}$ patients; those with advanced age, a smoking history, heart failure, systemic hypertension, or diabetes mellitus in the ICU at transplant time; those undergoing retransplantation; those with preexisting renal impairment; and those with MV or ECMO (16). Thus, screening patients who have such risk factors using a precise estimate of kidney function and continuing to monitor these patients until the risk has subsided is crucial. Lung transplant candidates and recipients with evidence of kidney injury and those at increased risk should be referred early for nephrology consultation because early involvement and coordination of care with nephrology can facilitate prompt diagnosis and preventive management to mitigate AKI (109). Smoking cessation and control of blood pressure and blood sugar levels may also be beneficial for reducing AKI occurrence and development.

\section{Volume management and maintenance of hemodynamic stability}

Perioperatively, optimal fluid management prevents volume depletion and maintains adequate renal perfusion. Careful monitoring of the urine output level and fluid balance can help reduce the mortality of AKI patients (110). For patients with hemodynamic instability, it is necessary to use a Swan-Ganz catheter and optimize the volume status and hemodynamic parameters to closely monitor hemodynamics. Diuretic use, vasopressor therapy and extracorporeal ultrafiltration should be adjusted based on fluid responsiveness and assessment of tolerance, and ventilator settings and lung recruitment maneuvers should be considered. Due to the potential for kidney toxicity, use of HES to perform fluid resuscitation is not recommended in most transplant patients (111).

\section{Optimization of immunosuppressive therapy (IST)}

The CNIs CsA and tacrolimus are the most effective drugs to prevent rejection reactions, but they are related to renal toxicity. A whole-blood CNI concentration beyond the treatment range is also associated with early-onset AKI $(36,112)$. Certain factors influence the pharmacokinetics of CNIs: altered liver metabolism and gut absorption, drug interactions (azoles, rifamycin), anemia, and hypoalbuminemia, causing great fluctuations in blood drug concentrations (16). Close monitoring of the CNI trough 
concentration is necessary and crucial for lung transplant recipients. For now, there seem to be no agents that can quickly replace the widespread use of CNIs. A CNI minimization strategy $(113,114)$ or conversion to a new immunosuppressive agent, such as belatacept $(115,116)$, requires further investigation.

\section{Limiting exposure to nephrotoxic agents}

Most posttransplant patients are likely to be exposed to different types of renal toxins due to infectious complications. Antimicrobials, such as vancomycin, aminoglycosides, trimethoprim-sulfamethoxazole, amphotericin, and ganciclovir/valganciclovir, can lead to renal injury (16). Furthermore, reducing the dosage of antibiotics in a timely manner according to culture results and clinical conditions is crucial. When these nephrotoxic drugs are imperative, they ought to be utilized in conjunction with suitable monitoring of trough levels if possible. Notably, NSAIDs should be avoided. Other potential nephrotoxic agents, such as radiocontrast agents, should be used only when essential, and if possible, a minimal amount of dye should be administered.

\section{Protective lung ventilation}

MV can have an impact on the cardiopulmonary system and systemic hemodynamics, further stimulating the neurohormonal system (14). Lung injury and AKI have a bidirectional interaction through a few cellular and pathophysiologic mechanisms (14). Studies have demonstrated that lung-protective ventilation mitigates volutrauma and barotrauma and reduces AKI risk by limiting the breath-induced hemodynamic effects and cytokines that burden the kidney (117). Therefore, during MV, a lung protection strategy should be adopted to maintain renal function.

\section{Early recognition and diagnosis of AKI}

The essentials of AKI management are recognition of the underlying etiology and supportive care. Both of these priorities could be ameliorated by recognizing AKI earlier and by closely monitoring renal function (110). $\mathrm{sCr}$ and urine output are the basis of AKI diagnosis, staging, and prognosis prediction. For transplant patients, close monitoring of $\mathrm{sCr}$ and urinary output levels is vital, particularly in high-risk AKI patients, which can result in earlier and better fluid management. As sCr can be affected by the nutritional status of patients, using AKI biomarkers that are independent of this condition for preoperative risk assessment and stratification may help clinicians take timely preventive measures (70).

\section{Appropriate utilization of renal replacement therapy}

Currently, there are no effective drugs to treat AKI, despite a significant need and historical trials (118). RRT should be considered in patients with volume overload, especially refractory hypoxemia, if conservative treatment fails. For patients on ECMO, RRT can be performed using either a built-in blood filter or by integrating a standard RRT machine into the ECMO loop (16), although many centers prefer venous access for RRT rather than an ECMO loop to reduce thrombosis in the latter (119). In addition, unlike the native kidney, RRT requires close monitoring to avert intradialytic hypotension, hypophosphatemia and hypokalemia $(16,119)$. Oral supplementation or addition of phosphorus/potassium to RRT solutions is necessary to avoid severe electrolyte disturbance.

\section{Next steps}

Identification of patients before the occurrence of early renal damage is essential. Several biomarkers have shown promising results in the identification of early renal damage, but the clinical applicability of these biomarkers needs further study. Renal protection strategies including pharmacotherapy, fluid replacement and nutritional support are another area of ongoing research. Combining renal protection strategies with the use of new biomarkers to develop early kidney risk identification and protection protocols is a promising idea that requires further research.

\section{Conclusions}

AKI after LT is common and can contribute to increased mortality and morbidity. Due to a variety of perioperative risk factors, AKI usually occurs early after transplantation. Importantly, in patients with high risk, appropriate management of perioperative hemodynamic changes, minimization of the use of nephrotoxic agents, and optimization of IST after LT can significantly reduce AKI severity and occurrence during the perioperative period. Appropriate monitoring for AKI, including the use of biomarkers, is necessary because early alerts and rapid nephrology intervention will impact outcomes. RRT 
should be considered when conservative treatment fails, and maintaining hemodynamic stability and electrolyte balance during RRT is crucial. Cross-disciplinary coordination for the care of patients with severe AKI after LT is recommended.

\section{Acknowledgments}

Funding: This work was supported by the Non-profit Central Research Institute Fund of Chinese Academy of Medical Sciences (2019PT320020).

\section{Footnote}

Reporting Checklist: The authors have completed the Narrative Review reporting checklist. Available at http:// dx.doi.org/10.21037/atm-20-7644

Conflicts of Interest: All authors have completed the ICMJE uniform disclosure form (available at http://dx.doi. org/10.21037/atm-20-7644). The authors have no conflicts of interest to declare.

Ethical Statement: The authors are accountable for all aspects of the work in ensuring that questions related to the accuracy or integrity of any part of the work are appropriately investigated and resolved.

Open Access Statement: This is an Open Access article distributed in accordance with the Creative Commons Attribution-NonCommercial-NoDerivs 4.0 International License (CC BY-NC-ND 4.0), which permits the noncommercial replication and distribution of the article with the strict proviso that no changes or edits are made and the original work is properly cited (including links to both the formal publication through the relevant DOI and the license). See: https://creativecommons.org/licenses/by-nc-nd/4.0/.

\section{References}

1. Lertjitbanjong P, Thongprayoon C, Cheungpasitporn $\mathrm{W}$, et al. Acute kidney injury after lung transplantation: asystematic review and meta-analysis. J Clin Med 2019;8:1713.

2. Mehta RL, Kellum JA, Shah SV, et al. Acute Kidney Injury Network: report of an initiative to improve outcomes in acute kidney injury. Crit Care 2007;11:R31.

3. Bellomo R, Ronco C, Kellum JA, et al. Acute renal failure - definition, outcome measures, animal models, fluid therapy and information technology needs: the Second International Consensus Conference of the Acute Dialysis Quality Initiative (ADQI) Group. Crit Care 2004;8:R204-12.

4. Kellum JA, Lameire N, Aspelin P, et al. Kidney disease: improving global outcomes (KDIGO) acute kidney injury work group. KDIGO clinical practice guideline for acute kidney injury. Kidney Int Suppl 2012;2:1-138.

5. Khwaja A. KDIGO clinical practice guidelines for acute kidney injury. Nephron 2012;120:c179-84.

6. Kellum JA, Lameire N. Diagnosis, evaluation, and management of acute kidney injury: a KDIGO summary (Part 1). Crit Care 2013;17:204.

7. Rocha PN, Rocha AT, Palmer SM, et al. Acute renal failure after lung transplantation: Incidence, predictors and impact on perioperative morbidity and mortality. Am J Transplant 2005;5:1469-76.

8. Wehbe E, Brock R, Budev M, et al. Short-term and long-term outcomes of acute kidney injury after lung transplantation. J Heart Lung Transplant 2012;31:244-51.

9. Fidalgo P, Ahmed M, Meyer SR, et al. Incidence and outcomes of acute kidney injury following orthotopic lung transplantation: a population-based cohort study. Nephrol Dial Transplant 2014;29:1702-9.

10. Jacques F, El-Hamamsy I, Fortier A, et al. Acute renal failure following lung transplantation: risk factors, mortality, and long-term consequences. Eur J Cardiothorac Surg 2012;41:193-9.

11. George TJ, Arnaoutakis GJ, Beaty CA, et al. Acute kidney injury increases mortality after lung transplantation. Ann Thorac Surg 2012;94:185-92.

12. Hoste EAJ, Bagshaw SM, Bellomo R, et al. Epidemiology of acute kidney injury in critically ill patients: the multinational AKI-EPI study. Intensive Care Med 2015;41:1411-23.

13. Cheungpasitporn W, Kashani K. Electronic data systems and acute kidney injury. Contrib Nephrol 2016;187:73-83.

14. Husain-Syed F, Slutsky AS, Ronco C. Lung-kidney crosstalk in the critically ill patient. Am J Respir Crit Care Med 2016;194:402-14.

15. Kilburn KH. Renal function in respiratory failure. Arch Intern Med 1971;127:754.

16. Puttarajappa CM, Bernardo JF, Kellum JA. Renal complications following lung transplantation and heart transplantation. Crit Care Clin 2019;35:61-73.

17. Bellomo R, Prowle JR, Echeverri JE. Diuretic therapy in fluid-overloaded and heart failure patients. Contrib 
Nephrol 2010;164:153-63.

18. Anand IS. Cardiorenal syndrome: acardiologist's perspective of pathophysiology. Clin J Am Soc Nephrol 2013;8:1800-7.

19. Carillo C, Pecoraro Y, Anile M, et al. Evaluation of renal function in patients undergoing lung transplantation. Transplant Proc 2017;49:699-701.

20. Pham PTT, Slavov C, Pham PCT. Acute kidney injury after liver, heart, and lung transplants: dialysis modality, predictors of renal function recovery, and impact on survival. Adv Chronic Kidney Dis 2009;16:256-67.

21. Barraclough K, Menahem SA, Bailey M, et al. Predictors of decline in renal function after lung transplantation. J Heart Lung Transplant 2006;25:1431-5.

22. Hill NR, Fatoba ST, Oke JL, et al. Global prevalence of chronic kidney disease - asystematic review and metaanalysis. PLoS One 2016;11:e0158765.

23. Jha V, Garcia-Garcia G, Iseki K, et al. Chronic kidney disease: global dimension and perspectives. Lancet 2013;382:260-72.

24. Norton JM, Moxey-Mims MM, Eggers PW, et al. Social determinants of racial disparities in CKD. J Am Soc Nephrol 2016;27:2576-95.

25. Xue J, Wang L, Chen CM, et al. Acute kidney injury influences mortality in lung transplantation. Ren Fail 2014;36:541-5.

26. Grimm JC, Lui C, Kilic A, et al. A risk score to predict acute renal failure in adult patients after lung transplantation. Ann Thorac Surg 2015;99:251-7.

27. Banga A, Mohanka M, Mullins J, et al. Characteristics and outcomes among patients with need for early dialysis after lung transplantation surgery. Clin Transplant 2017;31:1-9.

28. Ishani A, Erturk S, Hertz MI, et al. Predictors of renal function following lung or heart-lung transplantation. Kidney Int 2002;61:2228-34.

29. van den Akker JPC, Egal M, Groeneveld JAB. Invasive mechanical ventilation as a risk factor for acute kidney injury in the critically ill: a systematic review and metaanalysis. Crit Care 2013;17:R98.

30. Darmon M, Clec'h C, Adrie C, et al. Acute respiratory distress syndrome and risk of AKI among critically ill patients. Clin J Am Soc Nephrol 2014;9:1347-53.

31. Liu KD, Matthay MA. Advances in critical care for the nephrologist: acute lung injury/ARDS. Clin J Am Soc Nephrol 2008;3:578-86.

32. Chen H, Yu RG, Yin NN, et al. Combination of extracorporeal membrane oxygenation and continuous renal replacement therapy in critically ill patients: a systematic review. Crit Care 2014;18:675.

33. Haneya A, Diez C, Philipp A, et al. Impact of acute kidney injury on outcome in patients with severe acute respiratory failure receiving extracorporeal membrane oxygenation. Crit Care Med 2015;43:1898-906.

34. Thongprayoon C, Cheungpasitporn W, Lertjitbanjong $\mathrm{P}$, et al. Incidence and impact of acute kidney injury in patients receiving extracorporeal membrane oxygenation: ameta-analysis. J Clin Med 2019;8:981.

35. Robinson PD, Shroff RC, Spencer H. Renal complications following lung and heart-lung transplantation. Pediatr Nephrol 2013;28:375-86.

36. Sikma MA, Hunault CC, van de Graaf EA, et al. High tacrolimus blood concentrations early after lung transplantation and the risk of kidney injury. Eur J Clin Pharmacol 2017;73:573-80.

37. Shashaty MGS, Forker CM, Miano TA, et al. The association of post-lung transplant acute kidney injury with mortality is independent of primary graft dysfunction: a cohort study. Clin Transplant 2019;33:e13678.

38. Schindler R, Radke C, Paul K, et al. Renal problems after lung transplantation of cystic fibrosis patients. Nephrol Dial Transplant 2001;16:1324-8.

39. Katz SM, Krueger LJ, Falkner B. Microscopic nephrocalcinosis in cystic fibrosis. $\mathrm{N} \mathrm{Engl} \mathrm{J} \mathrm{Med}$ 1988;319:263-6.

40. Hellemons ME, Agarwal PK, van der Bij W, et al. Former smoking is a risk factor for chronic kidney disease after lung transplantation. Am J Transplant 2011;11:2490-8.

41. Fidalgo P, Ahmed M, Meyer SR, et al. Association between transient acute kidney injury and morbidity and mortality after lung transplantation: a retrospective cohort study. J Crit Care 2014;29:1028-34.

42. Atchade E, Barour S, Tran-Dinh A, et al. Acute kidney injury after lung transplantation: perioperative risk factors and outcome. Transplant Proc 2020;52:967-76.

43. Ishikawa $S$, Griesdale DEG, Lohser J. Acute kidney injury within 72 hours after lung transplantation: incidence and perioperative risk factors. J Cardiothorac Vasc Anesth 2014;28:931-5.

44. Balci MK, Vayvada M, Salturk C, et al. Incidence of early acute kidney injury in lung transplant patients: asinglecenter experience. Transplant Proc 2017;49:593-8.

45. Bihorac A, Delano MJ, Schold JD, et al. Incidence, clinical predictors, genomics, and outcome of acute kidney injury among trauma patients. Ann Surg 2010;252:158-65.

46. Nguyen AP, Gabriel RA, Golts E, et al. Severity of acute kidney injury in the post-lung transplant patient is 
associated with higher healthcare resources and cost. J Cardiothorac Vasc Anesth 2017;31:1361-9.

47. Shashaty MGS, Meyer NJ, Localio AR, et al. African american race, obesity, and blood product transfusion are risk factors for acute kidney injury in critically ill trauma patients. J Crit Care 2012;27:496-504.

48. Ma S, Evans RG, Iguchi N, et al. Sepsis-induced acute kidney injury: a disease of the microcirculation. Microcirculation 2019;26:e12483.

49. Auchet T, Regnier MA, Girerd N, et al. Outcome of patients with septic shock and high-dose vasopressor therapy. Ann Intensive Care 2017;7:43.

50. Brown SM, Lanspa MJ, Jones JP, et al. Survival after shock requiring high-dose vasopressor therapy. Chest 2013;143:664-71.

51. Kellum JA, Prowle JR. Paradigms of acute kidney injury in the intensive care setting. Nat Rev Nephrol 2018;14:217-30.

52. Korom S, Boehler A, Weder W. Immunosuppressive therapy in lung transplantation: state of the art. Eur J Cardiothorac Surg 2009;35:1045-55.

53. Bouchard J, Acharya A, Cerda J, et al. A prospective international multicenter study of AKI in the intensive care unit. Clin J Am Soc Nephrol 2015;10:1324-31.

54. Uchino $\mathrm{S}$. Acute renal failure in critically ill patients:amultinational, multicenter study. JAMA 2005;294:813-8.

55. Bennett D, Fossi A, Marchetti L, et al. Postoperative acute kidney injury in lung transplant recipients. Interact Cardiovasc Thorac Surg 2019;28:929-35.

56. Chen YC, Tsai FC, Chang CH, et al. Prognosis of patients on extracorporeal membrane oxygenation: the impact of acute kidney injury on mortality. Ann Thorac Surg 2011;91:137-42.

57. Lin CY, Tsai FC, Tian YC, et al. Evaluation of outcome scoring systems for patients on extracorporeal membrane oxygenation. Ann Thorac Surg 2007;84:1256-62.

58. Hansrivijit P, Lertjitbanjong P, Thongprayoon C, et al. Acute kidney injury in pediatric patients on extracorporeal membrane oxygenation: asystematic review and metaanalysis. Medicines 2019;6:109.

59. Goes NB, Colvin RB. Case 12-2007: a 56-year-old woman with renal failure after heart-lung transplantation. $\mathrm{N}$ Engl J Med 2007;356:1657-65.

60. Boyer NL, Niven A, Edelman J. Tacrolimus-associated thrombotic microangiopathy in a lung transplant recipient. BMJ Case Rep 2013;2013:bcr2012007351.

61. Binet I, Wallnöfer A, Weber C, et al. Renal hemodynamics and pharmacokinetics of bosentan with and without cyclosporine A. Kidney Int 2000;57:224-31.

62. Bloom RD, Doyle AM. Kidney disease after heart and lung transplantation. Am J Transplant 2006;6:671-9.

63. Högerle BA, Kohli N, Habibi-Parker K, et al. Challenging immunosuppression treatment in lung transplant recipients with kidney failure. Transpl Immunol 2016;35:18-22.

64. Peeters P, Van Laecke S, Vanholder R. Acute kidney injury in solid organ transplant recipients. Acta Clinica Belgica 2007;null:389-92.

65. Ahya VN, Doyle AM, Mendez JD, et al. Renal and vestibular toxicity due to inhaled tobramycin in a lung transplant recipient. J Heart Lung Transplant 2005;24:932-5.

66. Laporta R, Ussetti P, Carreno M. Renal toxicity due to inhaled tobramycin in lung transplant recipients. J Heart Lung Transplant 2006;25:608.

67. Sawhney S, Marks A, Fluck N, et al. Post-discharge kidney function is associated with subsequent ten-year renal progression risk among survivors of acute kidney injury. Kidney Int 2017;92:440-52.

68. Chambers DC, Cherikh WS, Harhay MO, et al. The international thoracic organ transplant registry of the International Society for Heart and Lung Transplantation: thirty-sixth adult lung and heart-lung transplantation report—2019; focus theme: donor and recipient size match. J Heart Lung Transplant 2019;38:1042-55.

69. Faubel S. SuPAR: a potential predictive biomarker for acute kidney injury. Nat Rev Nephrol 2020;16:375-6.

70. Pozzoli S, Simonini M, Manunta P. Predicting acute kidney injury: current status and future challenges. J Nephrol 2018;31:209-23.

71. Xu SY, Carlson M, Engström A, et al. Purification and characterization of a human neutrophil lipocalin (HNL) from the secondary granules of human neutrophils. Scand J Clin Lab Invest 1994;54:365-76.

72. Haase M, Bellomo R, Devarajan P, et al. Accuracy of neutrophil gelatinase-associated lipocalin (NGAL) in diagnosis and prognosis in acute kidney injury: asystematic review and meta-analysis. Am J Kidney Dis 2009;54:1012-24.

73. Hjortrup PB, Haase N, Wetterslev M, et al. Clinical review: predictive value of neutrophil gelatinase-associated lipocalin for acute kidney injury in intensive care patients. Crit Care 2013;17:211.

74. Singer E, Elger A, Elitok S, et al. Urinary neutrophil gelatinase-associated lipocalin distinguishes pre-renal from intrinsic renal failure and predicts outcomes. Kidney Int 
2011;80:405-14.

75. Shaw A. Update on acute kidney injury after cardiac surgery. J Thorac Cardiovasc Surg 2012;143:676-81.

76. Haase M, Haase-Fielitz A, Bellomo R, et al. Neutrophil gelatinase-associated lipocalin as a marker of acute renal disease. Curr Opin Hematol 2011;18:11-8.

77. Nickolas TL, O’Rourke MJ, Yang J, et al. Sensitivity and specificity of a single emergency department measurement of urinary neutrophil gelatinase-associated lipocalin for diagnosing acute kidney injury. Ann Intern Med 2008;148:810.

78. Bignami E, Frati E, Meroni R, et al. Urinary neutrophil gelatinase-associated lipocalin time course during cardiac surgery. Ann Card Anaesth 2015;18:39.

79. Schmidt-Ott KM, Mori K, Li JY, et al. Dual action of neutrophil gelatinase-associated lipocalin. J Am Soc Nephrol 2007;18:407-13.

80. Mårtensson J, Bell M, Xu S, et al. Association of plasma neutrophil gelatinase-associated lipocalin (NGAL) with sepsis and acute kidney dysfunction. Biomarkers 2013;18:349-56.

81. Mårtensson J, Bell M, Oldner A, et al. Neutrophil gelatinase-associated lipocalin in adult septic patients with and without acute kidney injury. Intensive Care Med 2010;36:1333-40.

82. Otto GP, Hurtado-Oliveros J, Chung HY, et al. Plasma neutrophil gelatinase-associated lipocalin is primarily related to inflammation during sepsis: atranslational approach. PLoS One 2015;10:e0124429.

83. Koyner JL, Zarbock A, Basu RK, et al. The impact of biomarkers of acute kidney injury on individual patient care. Nephrol Dial Transplant 2020;35:1295-305.

84. Price PM, Safirstein RL, Megyesi J. The cell cycle and acute kidney injury. Kidney Int 2009;76:604-13.

85. Oezkur M, Magyar A, Thomas P, et al. TIMP-2*IGFBP7 (Nephrocheck®) measurements at intensive care unit admission after cardiac surgery are predictive for acute kidney injury within 48 hours. Kidney Blood Press Res 2017;42:456-67.

86. Levante C, Ferrari F, Manenti C, et al. Routine adoption of TIMP2 and IGFBP7 biomarkers in cardiac surgery for early identification of acute kidney injury. Int J Artif Organs 2017;40:714-8.

87. Yang QH, Liu D, Long Y, et al. Acute renal failure during sepsis: potential role of cell cycle regulation. J Infect 2009;58:459-64.

88. Kashani K, Al-Khafaji A, Ardiles T, et al. Discovery and validation of cell cycle arrest biomarkers in human acute kidney injury. Crit Care 2013;17:R25.

89. Ichimura T, Bonventre JV, Bailly V, et al. Kidney injury molecule-1 (KIM-1), a putative epithelial cell adhesion molecule containing a novel immunoglobulin domain, is up-regulated in renal cells after Iinjury. J Biol Chem 1998;273:4135-42.

90. Han WK, Bailly V, Abichandani R, et al. Kidney injury molecule-1 (KIM-1): a novel biomarker for human renal proximal tubule injury. Kidney Int 2002;62:237-44.

91. Vaidya VS, Ramirez V, Ichimura T, et al. Urinary kidney injury molecule-1: a sensitive quantitative biomarker for early detection of kidney tubular injury. Am J Physiol Renal Physiol 2006;290:F517-29.

92. Ichimura T, Hung CC, Yang SA, et al. Kidney injury molecule-1: a tissue and urinary biomarker for nephrotoxicant-induced renal injury. Am J Physiol Renal Physiol 2004;286:F552-63.

93. Huang Y, Craig Don-Wauchope A. The clinical utility of kidney injury molecule 1 in the prediction, diagnosis and prognosis of acute kidney injury: asystematic review. Inflamm Allergy Drug Targets 2011;10:260-71.

94. Koyner JL, Vaidya VS, Bennett MR, et al. Urinary biomarkers in the clinical prognosis and early detection of acute kidney injury. Clin J Am Soc Nephrol 2010;5:2154-65.

95. Gauer S, Sichler O, Obermüller N, et al. IL-18 is expressed in the intercalated cell of human kidney. Kidney Int 2007;72:1081-7.

96. Parikh CR, Jani A, Melnikov VY, et al. Urinary interleukin-18 is a marker of human acute tubular necrosis. Am J Kidney Dis 2004;43:405-14.

97. Parikh CR, Mishra J, Thiessen-Philbrook H, et al. Urinary IL-18 is an early predictive biomarker of acute kidney injury after cardiac surgery. Kidney Int 2006;70:199-203.

98. Parikh CR, Abraham E, Ancukiewicz M, et al. Urine IL18 Is an early diagnostic marker for acute kidney injury and predicts mortality in the intensive care unit. J Am Soc Nephrol 2005;16:3046-52.

99. Gerard SK, Khayam-Bashi H. Characterization of creatinine error in ketotic patients: aprospective comparison of alkaline picrate methods with an enzymatic method. Am J Clin Pathol 1985;84:659-64.

100.Herget-Rosenthal S, Pietruck F, Volbracht L, et al. Serum cystatin C - a superior marker of rapidly reduced glomerular filtration after uninephrectomy in kidney donors compared to creatinine. Clin Nephrol 2005;64:41-6.

101.Koyner JL, Bennett MR, Worcester EM, et al. Urinary 
cystatin $\mathrm{C}$ as an early biomarker of acute kidney injury following adult cardiothoracic surgery. Kidney Int 2008;74:1059-69.

102.Dharnidharka VR, Kwon C, Stevens G. Serum cystatin $\mathrm{C}$ is superior to serum creatinine as a marker of kidney function: A meta-analysis. Am J Kidney Dis 2002;40:221-6.

103. Roos JF, Doust J, Tett SE, et al. Diagnostic accuracy of cystatin $\mathrm{C}$ compared to serum creatinine for the estimation of renal dysfunction in adults and children-a metaanalysis. Clin Biochem 2007;40:383-91.

104. Herget-Rosenthal S, Bökenkamp A, Hofmann W. How to estimate GFR-serum creatinine, serum cystatin C or equations? Clin Biochem 2007;40:153-61.

105. Séronie-Vivien S, Delanaye P, Piéroni L, et al. Cystatin $\mathrm{C}$ : current position and future prospects. Clin Chem Lab Med 2008;46:1664-86.

106. Thunø M, Macho B, Eugen-Olsen J. suPAR: the molecular crystal ball. Dis Markers 2009;27:157-72.

107. Wei C, Möller CC, Altintas MM, et al. Modification of kidney barrier function by the urokinase receptor. Nat Med 2008;14:55-63.

108. Hayek SS, Leaf DE, Tahhan AS, et al. Soluble urokinase receptor and acute kidney injury. $\mathrm{N}$ Engl J Med 2020;382:416-26.

109. Norman SP, Ojo AO. Chronic renal failure after transplantation of a nonrenal organ. Trends Transpl 2009;3:59-69.

110.Jin K, Murugan R, Sileanu FE, et al. Intensive monitoring of urine output is associated with increased detection of acute kidney injury and improved outcomes. Chest

Cite this article as: Jing L, Chen W, Guo L, Zhao L, Liang C, Chen J, Wang C. Acute kidney injury after lung transplantation: a narrative review. Ann Transl Med 2021;9(8):717. doi: 10.21037/ atm-20-7644
2017;152:972-9.

111. Wiedermann CJ, Dunzendorfer S, Gaioni LU, et al. Hyperoncotic colloids and acute kidney injury: a metaanalysis of randomized trials. Crit Care 2010;14:R191.

112. Tedesco D, Haragsim L. Cyclosporine: areview. J Transplant 2012;2012:230386.

113. Flechner SM, Kobashigawa J, Klintmalm G. Calcineurin inhibitor-sparing regimens in solid organ transplantation: focus on improving renal function and nephrotoxicity. Clin Transplant 2008;22:1-15.

114. Olyaei AJ, de Mattos AM, Bennett WM. Nephrotoxicity of immunosuppressive drugs: new insight and preventive strategies. Curr Opin Crit Care 2001;7:384-9.

115. Timofte I, Terrin M, Barr E, et al. Belatacept for renal rescue in lung transplant patients. Transpl Int 2016;29:453-63.

116. Brugière $\mathrm{O}$, Cazes $\mathrm{A}$, Champion L, et al. Fulminant acute respiratory distress syndrome after calcineurin inhibitorbelatacept conversion in a lung transplant recipient. Transplantation 2018;102:e255-6.

117.Joannidis M, Forni LG, Klein SJ, et al. Lung-kidney interactions in critically ill patients: consensus report of the Acute Disease Quality Initiative (ADQI) 21 Workgroup. Intensive Care Med 2020;46:654-72.

118. Gallagher KM, O'neill S, Harrison EM, et al. Recent early clinical drug development for acute kidney injury. Expert Opin Investig Drugs 2017;26:141-54.

119. Husain-Syed F, Ricci Z, Brodie D, et al. Extracorporeal organ support (ECOS) in critical illness and acute kidney injury: from native to artificial organ crosstalk. Intensive Care Med 2018;44:1447-59. 